\title{
Produção de sementes macho-estéreis em arroz ${ }^{(1)}$
}

\author{
Claudio Bragantini(2), Elcio Perpétuo Guimarães ${ }^{(2)}$ e Veridiano dos Anjos Cutrim ${ }^{(2)}$
}

\begin{abstract}
Resumo - A obtenção comercial de sementes da linhagem macho-estéril é uma das limitações para viabilizar a produção de híbridos de arroz (Oryza sativa L.). Este trabalho buscou estudar três proporções entre a linhagem macho-estéril (linhagem A) e a mantenedora (linhagem B). As proporções estudadas foram 8:4, 10:2 e 14:4. As características avaliadas para determinar qual das proporções apresenta maior potencial foram: número e porcentagem de grãos cheios por panículas, e número de grãos de pólen por unidade de área. A proporção 8:4 produziu maior porcentagem de grãos cheios por panícula que as outras duas, mas, proporcionalmente, ocupa maior área física com a linhagem B no campo. Foram observadas diferenças estatísticas na porcentagem de grãos cheios entre as amostras coletadas nas várias fileiras da linhagem A (diferentes distâncias da fonte polinizadora), e observou-se uma influência marcante com relação à direção predominante dos ventos. O número de grãos de pólen foi igual para todas as relações e distâncias da fonte de pólen; por isso, não foi o fator determinante das diferenças observadas em porcentagem de grãos cheios por panícula. Os resultados permitiram concluir que a proporção 10:2 é a de maior potencial para a produção comercial de sementes da linhagem macho-estéril.
\end{abstract}

Termos para indexação: Oryza sativa, progênie, híbridos, capacidade de produção, esterilidade masculina citoplasmática, polinização, métodos de melhoramento.

\section{Male-sterile rice seed production}

\begin{abstract}
Commercial male-sterile rice (Oryza sativa L.) seed production is one of the limitations to allow large scale hybrid seed production. This work studied three ratios between male-sterile line (A line) and maintainer (B line). The A:B ratios used in the study were: 8:4, 10:2 and 14:4. The evaluated traits to determine which ratio is more suitable were: number and percentage of filled grains per panicle and number of pollen grains per unit area. The 8:4 ratio produced statistically significant higher percentage of filled grains per panicle than the other two, but proportionally it requires more field area for the B line. Statistical differences were observed for percentage of filled grains per panicle among samples collected in the different rows at different distances from the pollen source. These results were strongly influenced by the predominant wind direction. The number of pollen grains was statistically the same for all ratios and distances, therefore it did not play a major role in percentage of filled grain per panicle. The results allow to conclude that 10:2 ratio has the highest potential for male-sterile line seeds production.
\end{abstract}

Index terms: Oryza sativa, progeny, hybrids, production capacity, cytoplasmic male sterility, pollination, breeding methods.

\section{Introdução}

O cultivo comercial de híbridos de arroz é uma realidade na China desde 1976, ano em que foram

\footnotetext{
(1) Aceito para publicação em 16 de fevereiro de 2000.

(2) Embrapa-Centro Nacional de Pesquisa de Arroz e Feijão, Caixa Postal 179, CEP 75375-000 Santo Antônio de Goiás, GO. E-mail: claudio@cnpaf.embrapa.br, eguimara@cnpaf.embrapa.br, cutrim@cnpaf.embrapa.br
}

plantados os primeiros 150.000 ha (Yuan \& Virmani, 1988). Atualmente, são plantados cerca de 19 milhões de ha (Mao et al., 1998). A produção de híbridos em arroz requer a participação de um sistema genético-citoplasmático de macho-esterilidade composto por três linhagens: uma, macho-estéril (linhagem A); uma, macho-fértil e com capacidade de manutenção da esterilidade da linhagem A, e que deve ser o mais semelhante possível à linhagem $\mathrm{A}$, que é conhecida como linhagem B; e outra, também ma- 
cho-fértil, mas com capacidade de restauração da fertilidade da linhagem A (linhagem R). A combinação das duas primeiras linhagens (A e B) produz sementes que originam plantas macho-estéreis (sementes da linhagem A), e o cruzamento entre as linhagens A e $\mathrm{R}$ produz as sementes híbridas, que originam plantas férteis.

Esse processo, desenvolvido pelos chineses, para ser viabilizado no campo de produção de sementes, requer uma série de atividades, que são descritas por Virmani \& Sharma (1993) como: a) plantio da linhagem macho-estéril e da linhagem polinizadora em diferentes datas, para sincronizar a floração; b) corte das folhas-bandeira das plantas para melhorar a circulação dos grãos de pólen; c) aplicação de ácido giberélico, para melhorar a emissão das panículas; e d) auxílio manual à polinização por meio do movimento das panículas com uma corda no período da floração, para aumentar a polinização.

A Embrapa-Centro Nacional de Pesquisa de Arroz e Feijão desenvolve pesquisas com arroz híbrido desde de 1984 (Guimarães et al., 1998). A prioridade dos trabalhos realizados até o presente esteve centrada no desenvolvimento de linhagens A e B, e na identificação de linhagens R, no germoplasma desenvolvido no programa de melhoramento genético do arroz irrigado. Até o momento, as atividades executadas neste programa permitiram obter os seguintes resultados: a) desenvolver uma linhagem A; b) identificar cerca de 500 linhagens restauradoras (linhagens R), e c) avaliar cerca de 900 combinações híbridas que produziram entre $15 \%$ e $45 \%$ mais grãos de que as cultivares comerciais de arroz irrigado.

Esses trabalhos permitiram ao País ter o domínio sobre a técnica de produção de híbridos em arroz; entretanto, para viabilizar o processo comercialmente, é necessário dominar os aspectos relativos à produção de sementes macho-estéreis e híbridas, e fazer com que os custos de produção permitam um aumento na rentabilidade para os agricultores.

A literatura internacional relata vários estudos que mostram a capacidade produtiva das linhagens A de arroz (Namai \& Kato, 1988; Peijin et al., 1994; Mao et al., 1998). Todavia, nas condições brasileiras, este é o primeiro estudo dessa natureza.
O objetivo deste trabalho foi determinar, no campo, a capacidade de produção de sementes de arroz de uma linhagem macho-estéril e a distribuição de grãos de pólen.

\section{Material e Métodos}

Este trabalho foi desenvolvido no Campo de Apoio à Pesquisa e Desenvolvimento do Tocantins (CAPDT), localizado em Formoso do Araguaia, Estado do Tocantins ( $11^{\circ} 48^{\prime} \mathrm{Sul}$ e $49^{\circ} 32^{\prime}$ Oeste, a $300 \mathrm{~m}$ de altitude), no período de maio a outubro de 1998. As sementes utilizadas foram as da linhagem IR58025A, com macho-esterilidade genético-citoplasmática, e sua respectiva mantenedora, a linhagem IR58025B. Ambas foram tratadas com Carboxin + Thiran na concentração de $3,0 \mathrm{~mL} / \mathrm{L}$ de água, e submetidas ao processo de pré-germinação durante as 24 horas anteriores à semeadura. As mudas para o transplantio foram preparadas em bandejas de $0,18 \mathrm{~m}^{2}$ $(0,30 \times 0,60 \mathrm{~m})$ utilizando-se uma densidade de semeadura de $180 \mathrm{~g}$ de sementes/bandeja. Com o objetivo de sincronizar a floração, as sementes da linhagem A foram semeadas em 15 de maio, e as da linhagem B, em três épocas distintas, sendo $1 / 3$ dois dias antes das da linhagem $\mathrm{A}$, $1 / 3$ no mesmo dia, e $1 / 3$ dois dias depois.

O transplantio foi mecanizado, utilizando-se uma transplantadora automotriz, da marca Yanmar, com capacidade de transplantio simultâneo de seis fileiras, com espaçamento fixo de $0,30 \mathrm{~m}$ entre fileiras e $0,15 \mathrm{~m}$ entre plantas dentro das fileiras.

Em 6 de junho, as plântulas das duas linhagens foram transplantadas em uma área de $2.500 \mathrm{~m}^{2}$, nas seguintes proporções de fileiras entre as linhagens A e B: 8:4, 10:2 e 14:4, que constituíram os três tratamentos estudados no presente trabalho. Como mencionado, a distância entre as fileiras da linhagem A foi mantida fixa $(0,30 \mathrm{~m})$ nas três proporções, mas as distâncias entre o polinizador (linhagem B) e as fileiras da linhagem A, variaram de acordo com as proporções.

Para estimular a emissão das panículas e facilitar a polinização, oito dias antes do início da floração de ambas as linhagens aplicou-se o ácido giberélico na concentração de $40 \mathrm{~g} / \mathrm{ha}$ em toda a área experimental. O período de floração ocorreu na primeira semana de setembro, quando foram coletadas amostras de grãos de pólen entre fileiras alternadas da linhagem A, nos dias 2, 4 e 6 de setembro para a análise de sua dispersão. A coleta foi realizada utilizando-se lâminas de vidro $(7,6$ x 2,5 cm) recobertas com silicone, colocadas $0,10 \mathrm{~m}$ acima das panículas, todas com a face recoberta de silicone voltada para a direção predominante dos ventos. A dispersão dos grãos de pólen foi 
avaliada utilizando-se cinco repetições. Durante o período de floração, a velocidade dos ventos oscilou entre 1,06 e $3,47 \mathrm{~km} / \mathrm{hora}(17,7$ a $57,8 \mathrm{~m} / \mathrm{s})$. As lâminas ficaram expostas das $7 \mathrm{~h}$ às $14 \mathrm{~h}$ nos dias de coleta dos grãos de pólen. Após a coleta, para facilitar a visualização e a contagem dos grãos de pólen, as lâminas foram submergidas em uma solução de iodo, e a contagem dos grãos de pólen foi feita por meio de uma lupa, e calculou-se a média de cinco áreas da lâmina tomadas ao acaso.

Na maturação, foi colhida, ao acaso, em $1 \mathrm{~m}$ de fileiras alternadas da linhagem A, uma panícula de dez plantas diferentes, para a determinação do número de grãos cheios e vazios para o cálculo das porcentagens de fertilidade e esterilidade. Os tratamentos, constituídos pelas três proporções entre as linhagens A e B e as diferentes distâncias entre elas, foram distribuídos em um delineamento experimental de blocos completos, em parcelas subdivididas, com cinco repetições. Foi realizada a análise de variância dos dados transformados em arc sen $\sqrt{\mathrm{X}}$ e a comparação das médias pelo teste de Scott \& Knott (1974).

\section{Resultados e Discussão}

A análise de variância apresentada na Tabela 1 mostra que foram obtidas diferenças altamente significativas, tanto entre as proporções avaliadas como entre as distâncias dentro das proporções. Este comportamento foi observado em relação às características número e porcentagem de grãos cheios por panícula. A porcentagem de grãos cheios por panícula foi o fator determinante na produção de sementes da linhagem macho-estéril. Os resultados apresentados na Tabela 2 mostram que, em média, a proporção de oito fileiras da linhagem A para quatro da B (8:4) produziu significativamente mais que as outras duas

Tabela 1. Análise de variância para as características número e porcentagem de grãos cheios por panícula.

\begin{tabular}{lrcc}
\hline Causas da & G.L. & \multicolumn{2}{c}{ QM } \\
\cline { 3 - 4 } variação & & $\begin{array}{c}\text { No de grãos } \\
\text { cheios/panícula }\end{array}$ & $\begin{array}{c}\text { Grãos } \\
\text { cheios/panícula }\end{array}$ \\
\hline Repetição (R) & 4 & $34855,46^{* *}$ & $0,002^{\text {ns }}$ \\
Proporção (P) & 2 & $98818,85^{* *}$ & $0,023^{* *}$ \\
Erro (a) & 8 & 4288,74 & 0,001 \\
Distância dentro & 13 & $75728,81^{* *}$ & $0,026^{* *}$ \\
de proporção & & 4476,07 & 0,01 \\
Erro (b) & 52 & & \\
\hline
\end{tabular}

nsNão significativo. **Significativo a $1 \%$ de probabilidade pelo teste $\mathrm{F}$. proporções (10:2 e 14:4). A produção de grãos cheios por amostra na proporção $8: 4(554,1)$ foi $18,4 \%$ superior à proporção 10:2 (452,2), e 21,9\% maior que a proporção 14:4 $(432,9)$.

Considerando que a produção de sementes da linhagem A, por unidade de área (hectare), é o parâmetro que interessa comercialmente, os resultados indicam que a proporção 10:2 deva ser a mais viável economicamente, visto que nesta proporção a linhagem A ocupa 83,3\% da área cultivada, enquanto nas proporções de $14: 4$ e 8:4 ela ocupa $77,8 \%$ e $66,7 \%$, respectivamente. Singh et al. (1998), utilizando as mesmas linhagens do presente trabalho e uma proporção fixa de 16:2, verificaram uma queda constante no número de grãos cheios, quando se aumentou a proporção de $2: 2$ para 16:2, e obtiveram as maiores produtividades com as proporções de $6: 2 \mathrm{e}$ 8:2, nas condições agroclimáticas das Filipinas. Virmani (1996), conduzindo estudos no mesmo país do trabalho anterior, também constatou que a produção de sementes híbridas de arroz foi diretamente proporcional ao aumento da área ocupada com a linhagem macho-estéril de $16 \%$ a $78 \%$, e que em proporções acima desse porcentual a produtividade declinou.

As observações realizadas em cada uma das fileiras da linhagem macho-estéril mostraram que, quanto mais próxima da linhagem polinizadora, maior a

Tabela 2. Porcentagem de grãos cheios por panícula por proporções entre a linhagem A (macho-estéril) e a linhagem B (mantenedora) ensaiadas e por locais de $\operatorname{amostragem}^{(1)}$.

\begin{tabular}{cccc}
\hline \multirow{2}{*}{$\begin{array}{c}\text { Fileira de coleta } \\
\text { dos grãos }\end{array}$} & \multicolumn{3}{c}{ Proporções A:B } \\
\cline { 2 - 4 } & $8: 4$ & $10: 2$ & $14: 4$ \\
\hline & $---------1----(\%)-------$ \\
3 & $39,7 \mathrm{~A}$ & $40,0 \mathrm{~A}$ & $33,8 \mathrm{~A}$ \\
5 & $26,9 \mathrm{~B}$ & $25,4 \mathrm{~B}$ & $27,7 \mathrm{~B}$ \\
7 & $26,2 \mathrm{~B}$ & $20,0 \mathrm{C}$ & $22,2 \mathrm{C}$ \\
9 & $23,2 \mathrm{~B}$ & $18,6 \mathrm{C}$ & $16,5 \mathrm{C}$ \\
11 & & $19,9 \mathrm{C}$ & $20,0 \mathrm{C}$ \\
13 & & & $20,2 \mathrm{C}$ \\
\hline Média & & & $21,0 \mathrm{C}$ \\
\hline
\end{tabular}

${ }^{(1)}$ Valores seguidos pela mesma letra, maiúscula na coluna e minúscula na linha, não diferem entre si pelo teste de Scott \& Knott (1974), a 5\% de probabilidade. 
produção de grãos cheios por panícula, independentemente da proporção estudada. Entretanto, foi marcante a influência da direção predominante dos ventos. Fileiras que se encontravam próximas à fonte polinizadora, mas contrárias à direção dos ventos, produziram significativamente menos grãos cheios por panícula do que as que estavam próximas ao polinizador e na direção dos ventos; porém, constata-se que a quantidade disponível de grãos de pólen não influenciou a porcentagem de grãos cheios. Esses resultados podem ser observados na Figura $1 \mathrm{e}$ na Tabela 3.
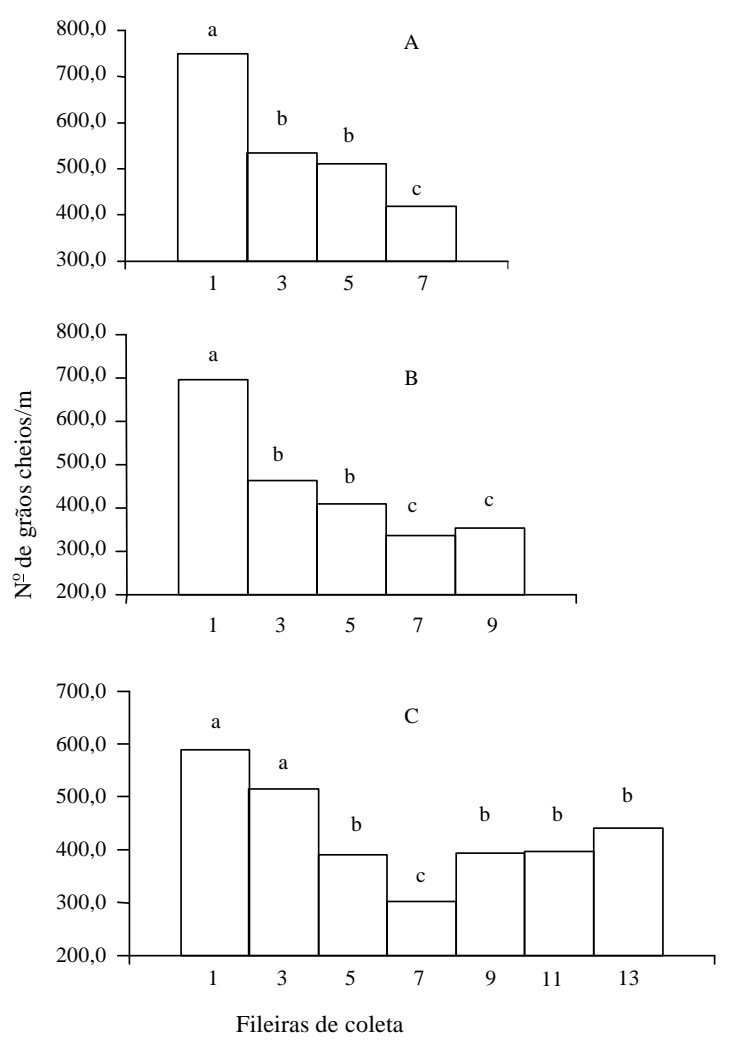

Figura 1. Número de grãos cheios por panícula nas fileiras na proporção entre a linhagem $\mathrm{A}$ (macho-estéril) e a linhagem B (mantenedora) de 8:4 (A), 10:2 (B) e 14:4 (C). As fileiras mais próximas ao polinizador são: 1 e 7 em A; 1 e 9 em B e 1 e 13 em C. A direção predominante do vento é da fileira 1 a $7 \mathrm{em} \mathrm{A}$; da fileira 1 a $9 \mathrm{em} \mathrm{B}$ e da fileira 1 a $13 \mathrm{em} \mathrm{C}$. Em cada proporção avaliada, as fileiras com a mesma letra não diferem entre si a 5\% de probabilidade pelo teste de Sott \& Knott (1974).
Quando se analisa o número de grãos cheios por panícula, os resultados observados são similares aos obtidos na análise da porcentagem de grãos cheios. A proporção de 10:2, que se mostrou de maior interesse para essa característica neste estudo, apresentou produção de 696,4 grãos cheios por panícula na fileira mais próxima ao polinizador e na direção predominante dos ventos, porém somente 353,6 grãos cheios, na fileira próxima ao polinizador mas na posição contrária aos ventos (Figura 1B). Essa diferença foi estatisticamente significativa. Para a proporção 8:4, os valores foram 750,6 e 419,6, e para 14:4, foram de 590,2 e 441,2, respectivamente (Figura 1A e 1C). Ambos os valores também foram estatisticamente significativos.

Constatou-se um ponto de valor mais baixo em relação à produção de grãos cheios por panícula, $\mathrm{o}$ qual ocorreu na sétima fileira nas proporções 10:2 e 14:4 (Figura 1B e 1C). Este resultado está indicando que essa parece ser a distância máxima a ser mantida entre a linhagem polinizadora $\mathrm{B}$ e a receptora $\mathrm{A}$, quando as condições ambientais, principalmente a velocidade e a frequiência dos ventos, forem semelhantes às observadas no CAPDT, e as características das linhagens A e B forem similares às das utilizadas neste trabalho.

Tabela 3. Número de grãos de pólen por unidade de campo do microscópio nas proporções entre a linhagem A (macho-estéril) e a linhagem B (mantenedora) nos diferentes locais de coleta.

\begin{tabular}{|c|c|c|c|}
\hline \multirow{2}{*}{$\begin{array}{l}\text { Local de coleta } \\
\text { dos grãos de } \\
\text { pólen }^{(1)}\end{array}$} & \multicolumn{3}{|c|}{ Proporções A:B } \\
\hline & $8: 4$ & $10: 2$ & $14: 4$ \\
\hline & ------ & $\left(n^{0}\right)$ & ---- \\
\hline 1 & 8,44 & 6,76 & 11,40 \\
\hline 2 & 8,88 & 8,40 & 9,40 \\
\hline 3 & 8,40 & 7,80 & 9,08 \\
\hline 4 & 9,16 & 6,28 & 7,88 \\
\hline 5 & & 5,88 & 9,40 \\
\hline 6 & & & 7,04 \\
\hline 7 & & & 7,04 \\
\hline
\end{tabular}

(1)Local 1: amostra coletada entre as fileiras 1 e 2; local 2: entre as fileiras 3 e 4; local 3: entre as fileiras 5 e 6; local 4: entre as fileiras 7 e 8; local 5: entre as fileiras 9 e 10; local 6: entre as fileiras 11 e 12; local 7: entre as fileiras 13 e 14 
Como mencionado, para auxiliar na compreensão do processo de produção de sementes da linhagem A foram coletadas amostras de grãos de pólen, próximas às fileiras em que foram coletadas as panículas para a determinação da porcentagem de produção de grãos. A Tabela 3 mostra os resultados obtidos quanto a esta característica na data de maior disponibilidade de grãos de pólen ( 2 de setembro). Não foram detectadas diferenças estatísticas significativas entre as quantidades coletadas nas fileiras das três proporções, ou seja, não houve influência da distância do polinizador na quantidade de grãos de pólen disponível para a polinização das plantas da linhagem A. Este resultado discorda dos relatados por Namai \& Kato (1988), Virmani (1996) e Mao et al. (1998), que encontraram correlações negativas entre a distância do polinizador e a quantidade de grãos de pólen disponível. Isso pode ser atribuído ao fato de, no presente trabalho, a velocidade dos ventos, no período de floração das linhagens, ter variado entre 17,7 e $57,8 \mathrm{~m} / \mathrm{s}$, enquanto nos trabalhos citados a velocidade média dos ventos variou de 2 a $3 \mathrm{~m} / \mathrm{s}$.

\section{Conclusões}

1. A proporção de dez fileiras da linhagem A para duas da B (10:2) é a mais recomendada para a produção comercial de sementes da linhagem machoestéril.

2. A direção predominante dos ventos e a distância do polinizador são aspectos importantes para a produção de sementes da linhagem macho-estéril.

3. A quantidade de grãos de pólen disponível nas diferentes fileiras ou distâncias, no momento da polinização, não afeta a produção de grãos cheios por panícula.

\section{Referências}

GUIMARÃES, E. P.; CUTRIM, V. A.; MENDONÇA, J. A. Developing hybrid rice in Brazil: methodology, highlights, and prospects. In: VIRMANI, S. S.; SIDDIQ, E. A.; MURALIDHARAN, K. (Ed.). Advances in hybrid rice technology. Manila : IRRI, 1998. p. 379-387.

MAO, C. X.; VIRMANI, S. S.; KUMAR, I. Technological innovations to lower the costs of hybrid seed production. In: VIRMANI, S. S.; SIDDIQ, E. A.; MURALIDHARAN, $\mathrm{K}$. (Ed.). Advances in hybrid rice technology. Manila : IRRI, 1998. p. 111-128.

NAMAI, H.; KATO, H. Improving pollination characteristics of japonica rice. In: INTERNATIONAL RICE RESEARCH INSTITUTE (Los Baños, Filipinas). Hybrid rice. Manila, 1988. p. 164-172.

PEIJIN, H.; MARUYAMA, K.; SHARMA, H. L.; VIRMANI, S. S. Advances in hybrid rice seed production technology. In: VIRMANI, S. S. (Ed.). Hybrid rice technology: new developments and future prospects. Los Baños : IRRI, 1994. p. 63-70.

SCOTT, A. J.; KNOTT, M. A. Cluster analysis method for grouping means in the analysis of variance. Biometrics, Washington, v. 30, p. 507-512, 1974.

SINGH, S.; VIRAKTAMATH, B. C.; VIJAYAKUMAR, C. H. M.; RAMESHA, M. S.; AHMED, M. I. Standardizing hybrid rice seed production practices. International Rice Research Notes, Manila, v. 23, n. 1, p. 22, 1998 .

VIRMANI, S. S. Hybrid rice. Advances in Agronomy, San Diego, v. 57, p. 377-462, 1996.

VIRMANI, S. S.; SHARMA, H. L. Manual for hybrid rice seed production. Manila : IRRI, 1993. $57 \mathrm{p}$.

YUAN, L. P.; VIRMANI, S. S. Status of hybrid rice research and development. In: INTERNATIONAL RICE RESEARCH INSTITUTE (Los Baños, Filipinas). Hybrid rice. Manila, 1988. p. 7-24. 